\title{
Introducing Strong Forms of Bilingual Education in the Mainstream Classroom: A Case for Technology
}

\author{
Marie-Luce Bourguet \\ Queen Mary, University of London \\ mlb@dcs.qmul.ac.uk
}

\begin{abstract}
Bilingual education programs whose aim is to support the development of balanced bilingualism belong to "strong" forms of bilingual education. Other desired outcomes of strong forms of bilingual education are cognitive advantages and better school achievement. The goal of our research is to explore how technology can help introducing strong forms of bilingual education for minority language children in mainstream classrooms. We present a first prototype (the OCOL model) that successfully recreates a bilingual learning environment. A study into the prototype shows that appropriate technology can help children achieve balanced bilingualism and biliteracy. We then discuss the aims, requirements and enabling technologies for the deployment of bilingual educational systems for children in mainstream education. Key areas for further research are identified and discussed: supporting bilingual language development, supporting curriculum acquisition in two languages, providing fair assessment tools, and improving communication and collaboration in multilingual environments.
\end{abstract}

\section{Introduction}

Defining bilingualism is difficult. There are four basic language abilities (listening, speaking, reading, and writing) for which bilingual individuals can exhibit different degrees of proficiency in each of their languages. Conveniently, the term "balanced bilinguals" refers to individuals whom competences in both languages are equally well developed. Balanced bilingualism also implies biliteracy, which describes the ability of reading and writing in two languages. For example, a child who can understand the delivery of the curriculum in school and operate in classroom activity in either language would be considered a balanced bilingual $[1$, p. 7]. Research has shown that balanced bilingual children are likely to benefit from cognitive advantages, such as superior divergent and creative thinking, as well as increased meta-linguistic awareness and communicative sensitivity [2].

However, achieving balanced bilingualism is not a simple affair. Some children, so-called elite bilinguals, benefit from an environment that allows them to develop their bilingualism: they belong to high status groups, they have access to adapted educational material such as bilingual books, and they may benefit from "strong" forms of bilingual education (which will be explained later). But the vast majority of children that come from a minority language background (typically the children of newly arrived immigrants) do not have this chance. They normally attend mainstream classrooms where their bilingualism is not fostered and does not develop. Minority language children who are placed in mainstream classrooms where the only medium of instruction is the majority language, are said to be in "submersion education" [1, p. 195]. Submersion education is a "weak" form of bilingual education, whose aim is assimilation and monolingualism. Another frequent outcome of submersion education is school underachievement and high dropout rates.

According to Cummins [5], it often takes one or two years for a child to acquire context-embedded second language fluency (i.e. conversational speech where there is a good degree of support in communication via body language and situational context), but it takes five to seven years to acquire context-reduced fluency, which is the type of fluency that is necessary to engage in the higher order cognitive processes of the classroom. The "common underlying proficiency model" of bilingualism [6] considers that both languages of a bilingual individual operate through the same central processing system. This model helps explain why, for children who are made to operate in a poorly developed language (as is the case in 
submersion education), cognitive functioning and academic performance may be negatively affected.

According to Krashen [12], bilingual education should be defined as a means of using the child's first language to accelerate the acquisition of a second language. Teaching curriculum content (e.g. math) in the child's first language provides knowledge, which helps the child understand instruction when it is presented in the second language (so the child learns more math and acquire more second language, because the math they hear in the second language is more comprehensible). Providing literacy development in the first language also accelerates the acquisition of second language literacy, as the ability to read transfers rapidly across languages, even when the writing systems are different [15].

Bilingual education programs whose aim is to support the development of balanced bilingualism belong to "strong" forms of bilingual education. Other desired outcomes of strong forms of bilingual education are cognitive advantages and better school achievement. The goal of our research is to explore how technology can help providing strong forms of bilingual education to minority language children in submersion education.

The paper is organized as follows: the next section describes two types of strong forms of bilingual education. In section 3, we present a first prototype system whose goal is to support balanced bilingualism acquisition through technology. In section 4, we discuss the requirements and enabling technologies for the deployment in mainstream classrooms of educational systems that can foster balanced bilingualism in minority language children. In section 5 , we draw some conclusions.

\section{Strong forms of bilingual education}

The expected outcome of strong forms of bilingual education is balanced bilingualism. In this section, we present two types of strong forms of bilingual education where part of the curriculum is taught in the child's first language. They are: developmental maintenance bilingual education (also called heritage language education), and dual (or two-way) language bilingual education.

In developmental maintenance bilingual education programs, all or most of the children come from language minority homes, and the minority language is typically used for half or more of the curriculum time. Where a minority language is used for a majority of classroom time (e.g. 80\%), the justification is that a minority language is easily lost whereas a majority language is easily gained (through television, shops and signs, videos and visits), and that children easily transfer ideas, concepts, skills and knowledge from the minority language into the majority language $[1, \mathrm{p}$. 210]. Developmental maintenance schools are usually fee-paying private schools, and the students tend to come from middle-class backgrounds.

The results of evaluation studies of developmental maintenance education programs suggest that these programs are effective: not only do the children maintain their home language, but they tend to perform at least as well as comparable mainstream children in all areas of the curriculum and in the majority language. Their sense of identity and self-esteem are enhanced [7].

Dual language (or two-way) bilingual education typically occurs when approximately equal numbers of language minority and language majority children are in the same classroom [1, p. 212]. In order to establish clear boundaries between the two languages, language separation is achieved by teaching different curriculum areas through different languages (e.g. social studies and art may be taught in the minority language, whereas math and technology are taught in the majority language); or the two languages are separated according to person (different teachers use different languages), according to time (e.g. one day may be through the minority language, and the following day through the majority language), or according to place. Language integration, on the other hand, can be achieved through the use of "translanguaging" where, for example, the teacher introduces a topic in the majority language and then makes some remarks in the minority language, or where hand-outs and work sheets are in one language and class activities are carried out in the other language.

Lindholm-Leary [13] has shown that children in dual language programs were performing about 10 points higher in reading achievement and math tests than the Californian state average for English speaking children educated in English only. One additional outcome of dual language education is positive crosscultural behaviours, and high levels of personal and social competence, which mostly results from the two languages of the school having equal status, and from children having very positive attitudes [13].

Dutcher [7] claims that strong forms of bilingual education create cost savings for the education system and for society, by providing higher levels of achievement in less years of study, whereas weak forms of bilingual education (e.g. submersion education), incur higher dropout rates, which mean lower potential for the employment market. In this paper, we claim that 
the use of technology could be an effective way of introducing strong forms of bilingual education in mainstream classrooms, hence achieving all or most of the benefits of strong forms of bilingual education without the direct cost of establishing special programs for minority language children and providing special training for teachers. Technology could also make it possible to address a wider variety of languages and children in a single classroom, and contribute to improving communication between minority language families and schools.

\section{Case study: the OCOL (One Character One Language) model}

The OCOL model is an attempt at implementing dual language bilingual education through technology $[3,4]$. The main concept in OCOL is the implementation of several software characters, each speaking to the other characters in their own language. An important assumption in the model is that all characters do understand the languages used by others, as in a dual language bilingual classroom. The two languages are thus well integrated in the system, but the separation is achieved by assigning different speakers to different languages. The model takes its inspiration from the popular OPOL (On Parent One Language) strategy for bringing up bilingual children in bilingual and/or bicultural families [8].

An OCOL prototype was developed as a Macromedia Director application for English and Japanese bilingual children aged 6 to 8 [3]. The system is designed as a story and the plot features two children: a bilingual boy from England named Bob, and a bilingual girl from Japan named Aiko. Dialogues are implemented between the two children, where vocabulary in both languages is used to talk about a number of relevant domains (e.g. school and home). Exercises are integrated into the story, e.g. vocabulary exercises to learn about what is found in a typical Japanese home. Each story is followed by literacy exercises that exploit the vocabulary just learnt.

The OCOL model was tested with the help of 4 children and 8 teachers in a Saturday morning Japanese school in London [4]. The children were all from bicultural families, they were bilingual in English and Japanese and aged from 6 to 8 (average: 6.5 years). All of the teachers were native Japanese speakers, with good knowledge of English, who had taught bilingual children of the age group tested. Results of the study (of which details can be found in [4]) suggest that a system like OCOL can support balanced bilingualism acquisition by helping to overcome the imbalance of knowledge that a bilingual child has of two languages. Providing diverse situations where children may use their languages meant that children would become able to use their weaker language in unfamiliar domains. From the testing it was clear that even though children may choose to go to a domain with which they are most familiar at first, they will eventually explore the whole system. All the children enjoyed using the system. The teachers also approved the OCOL model. In particular, they thought that it would help the assessment of bilingual children progress, even in situations where the teacher cannot speak the two languages.

OCOL was a first step towards exploring how technology can help support the acquisition of balanced bilingualism. However, the children who tested it were children from bicultural families who were already getting support in their minority language (Japanese) from a Saturday morning school. To support minority language children in submersion education, a clear statement of the system's aims and requirements, as well as a list of enabling technologies and related areas of research need to be established.

\section{Fostering bilingualism in the mainstream classroom}

\subsection{Challenge}

Despite the political controversy surrounding bilingual education in countries like the United States and Canada, these countries benefit from the availability of bilingual schools and programs. Such programs are not as readily available in the UK. Some schools in inner London, especially in areas where the freshly arrived immigrant population tend to concentrate, welcome children from very diverse geographical backgrounds, and can have as many as half a dozen of different languages spoken in a single classroom. The proficiency levels in first language and second language (English) also tend to be very heterogeneous among the children. The teachers do not speak the minority languages. Sometimes, extra support in English is provided in the form of pull-out sessions during which children are temporarily withdrawn from the class in order to receive compensatory lessons in English. When withdrawn from the class, the children are missing on the content delivered in the mainstream classroom and there may also be a stigma for absence [1, p. 197].

A technology-based solution (which we will call "the system") to the difficulties faced by submersion education children should provide support in the following areas: bilingual language development, 
curriculum acquisition, fair assessment, and improved communication.

\subsection{Bilingual development}

The system should support the development of first language and second language skills in all areas of language proficiency (speaking, listening, reading, and writing).

The OCOL model proved successful in promoting the acquisition of balanced bilingualism and could easily be incorporated in the system, in the form of games, dialogues, or narratives where both languages are used concurrently. In OCOL, both languages hold a position of equal prestige and importance. It is expected that the child will improve language competencies by transferring knowledge and skills from one language to the other. In particular, the child is encouraged to extend her vocabulary into domains in which she typically uses only one language. A system like OCOL also offers the opportunity of increasing a child's exposure to cultural elements of the countries where her languages are spoken.

It has been argued that the availability of reading material in a print-rich environment is key to the success of literacy development [11]. The system could provide the ideal platform for accessing online reading material such as books available from the International Children's Digital Library [17] (which currently contains 913 free children books written in 34 different languages).

\subsection{Curriculum acquisition}

The system should provide personalised content in all areas of the curriculum. In particular, curriculum material should be presented in a child's first language whenever majority language proficiency is not developed enough for understanding academic content.

Researchers in Cross-Language Information Retrieval (for example [14]), strive to find solutions to the difficult problem of matching an information need expressed in a user's native language (e.g. English) with documents in another language (e.g. the child's minority language). The system could apply crosslanguage information retrieval techniques in order to allow a teacher to input in English the key concepts of a lesson to be learnt, while relevant material in the child's minority language is retrieved from some digital learning resources. Such resources are currently being developed in the form of collections of learning objects [16]. An important characteristic of digital learning objects is that they are tagged with metadata, which means that every learning object has descriptive information allowing it to be easily found by a search. The success of the system would thus be dependent on the availability of learning object resources in different languages.

The system can also guarantee that there is good coordination, integration, and synchronization of content in the first and second language to ensure learning is cumulative and not repetitive [1, p. 352].

\subsection{Fair assessment}

The system should serve as a fair and broad assessment tool, by providing opportunities to assess a child in her first language.

It has been suggested that fair assessment of bilingual children need a wide diversity of measurement and observation devices over a period of time [9]. A good solution is portfolio type assessment where the system can be used for collecting samples of a child's natural communication and work in different roles and different situations (in the class and at home). For this, the system must be deployed on a mobile platform that the child can easily carry around and take home. Every usage of the system and interaction with it can also be recorded and included in the child's portfolio. Researchers on Children HCI (Human Computer Interaction) are currently studying how current and new interaction techniques (e.g. speech recognition, pen interfaces, etc.) can be best adapted to the needs and capabilities of children.

\subsection{Communication}

The system should serve as a communication tool between the child and the teacher, between children in the class, and between the school and the families. The system must not isolate the minority language student from the rest of the class, but should, at contrary, offer more and better opportunities for interaction.

The system's connectivity could allow a child to become an active participant in virtual learning communities that would help breaking a feeling of isolation. According to Holt [10], supportive and nonthreatening cooperative learning techniques that stress interdependence, social interaction and teamwork have been successfully used with culturally and linguistically diverse students. The concept of virtual learning communities is becoming increasingly popular. The ETHNOCLIC project for example [18], which is supported by the eContent European Action Plan, allows a world-wide network of French, English and Spanish speaking children (7-14 years old) to produce 
and exchange original documents relating to their daily lives. The CoLabs project [19] (under the EU Minerva programme) is developing new tools to allow children living at any location and within any culture to succeed in learning while collaborating and communicating at a distance. Where opportunities for active participation in the mainstream classroom may be limited for minority language children, providing access to peer networks would allow the children to become full participants in virtual learning communities. When the whole class subscribes to such a community, the position and the role of the minority language student may be enhanced, and communication with the rest of the class could also benefit.

\section{Conclusion}

Language should be seen as a personal and national resource, and not as a threat [1, p. 373]. The potential benefits of introducing strong forms of bilingual education for minority language children in submersion education are considerable. They include: stronger children's identity and empowerment, better school achievement, and smaller dropout rates.

In this paper, we have identified a number of current and past projects, existing and new lines of research that would successfully inspire or feed in the development of a bilingual educational system for minority language students in mainstream education. This paper also constitutes a call for better sharing of learning resources in different languages (reading material and learning objects). It is also a call for interdisciplinary research and collaborations among educational technologists, linguists, researchers in children $\mathrm{HCI}$ and in cross-language information retrieval.

\section{References}

[1] C. Baker, Foundation of Bilingual Education and Bilingualism, $3^{\text {rd }}$ Edition, Multilingual Matters Ltd., Clevedon, 2003.

[2] E. Bialystok, Bilingualism in Development: Language, Literacy, and Cognition, Cambridge University Press, Cambridge, 2001.

[3] M.L. Bourguet, and M.K. Plaha, "Technology-Mediated Learning Experiences: the OCOL (One Character One Language) model", in Proc. ICALT 04, IEEE Computer Society Press, 2004, pp. 515-519.

[4] M.L. Bourguet, M.K. Plaha, and N. Bryan-Kinns, "Computer Assisted Learning for Young Bilinguals", Academic Exchange Quarterly, 9 (3), 2005, pp. 267-271.
[5] J. Cummins, "Cognitive/academic language proficiency, linguistic interdependence, the optimum age question", Working Papers on Bilingualism, 19, 1979, pp. 121-129.

[6] J. Cummins, "The construction of language proficiency in bilingual education", in J.E. Alatis (Ed.) Georgetwon University Round Table on language and Linguistics, Georgetown University Press, Washington DC, 1980.

[7] N. Dutcher, The Use of First and Second Languages in education: A Review of International Experience, World bank, Washington DC, 1995.

[8] E. Harding, and P. Riley, The bilingual family, Cambridge University Press, Cambridge, 1986.

[9] R. Hernandez, "Reducing bias in the assessment of culturally and linguistically diverse populations", Journal of Educational Issues of Language Minority Students 14, 1994, pp. 269-300.

[10] D. Holt, Cooperative Learning: A response to Linguistic and Cultural Diversity, Center for Applied Linguistic and Delta Systems, 1993.

[11] S. Hudelson, "Literacy development of second language children”, in F. Genesee (Ed.), Educating Second Language Children, Cambridge University Press, Cambridge, 1994.

[12] S. Krashen, and G. McField. "What works? Reviewing the latest evedence on bilingual education", Language Learner 1(2), 2005, pp. 7-10.

[13] K. Lindholm-Leary, Dual Language Education, Multilingual Matters Ltd., Clevedon, 2001.

[14] C. Monz, and B. Dorr, "Iterative Translation Disambiguation for Cross-Language Information Retrieval", In Proc. 28th Annual International ACM SIGIR Conference on Research and Development in Information Retrieval, 2005, pp. 520-527.

[15] T. Odlin, Language transfer: Cross-linguistic influence in language learning, Cambridge University Press, Cambridge, 1989.

[16] IEEE 1484.12.1-2002, Draft Standard for Learning Object Metadata, IEEE Learning Technology Standards Committee (LTSC), 2002.

[17] International Children's Digital library http://www.icdlbooks.org

[18] ETHNOCLIC: Ethnological tools for cultural diversity and language

http://www.ethnokids.asso.fr/Proto2/

[19] Co-Labs: An European investigation project. http://matchsz.inf.elte.hu/Colabs/ 